\title{
Covid-19 pandemic impact on colonoscopy service and suggestions for managing recovery
}

\section{다 (용}

\section{Authors}

Sergio Cadoni ${ }^{*}, 1$, Sauid Ishaq ${ }^{*, 2,3}$, Cesare Hassan ${ }^{4}$, Pradeep Bhandari ${ }^{5}$, Helmut Neumann ${ }^{6}$, Toshio Kuwai ${ }^{7}$, Noriya Uedo ${ }^{8}$, Adolfo Parra-Blanco ${ }^{9}$, Chris J.J. Mulder ${ }^{10}$, Kenneth F. Binmoeller ${ }^{11}$, Felix W. Leung ${ }^{12,13}$

\section{Institutions}

1 CTO Hospital, Digestive Endoscopy Unit, Iglesias, Italy

2 Russell Hall, Dept. of Gastroenterology, Birmingham, United Kingdom

3 Birmingham City University, Birmingham, United Kingdom

4 Nuovo Regina Margherita Hospital, Gastroenterology, Italy

5 Portsmouth University Hospital, Dept. of Gastroenterology, Portsmouth, United Kingdom

6 University Medical Center Mainz, Interventional Endoscopy Center, I. Medizinische Klinik und Poliklinik, Mainz, Germany

7 National Hospital Organization Kure Medical Center and Chugoku Cancer Center, Gastroenterology, Kure, Japan

8 Osaka International Cancer Institute, Department of Gastrointestinal Oncology, Osaka, Japan

9 NIHR Nottingham Digestive Diseases Biomedical Research Centre, Nottingham University Hospitals NHS Trust, Gastroenterology, Nottingham, United Kingdom

10 VU University Medical Center, Dept. of Gastroenterology, Arnhem, Netherlands

11 California Pacific Medical Center, California, United States

12 Veteran Affairs Greater Los Angeles Healthcare System, Sepulveda Ambulatory Care Center, California, United States

13 David Geffen School of Medicine at UCLA, Medicine, North Hills, California, United States.

submitted 19.5.2020

accepted after revision 5.6 .2020
Bibliography

DOI https://doi.org/10.1055/a-1196-1711 |

Endoscopy International Open 2020; 08: E985-E989

(c) Georg Thieme Verlag KG Stuttgart · New York

eISSN 2196-9736

Corresponding author

Prof. Sauid Ishaq, Department of Gastroenterology, Birmingham City University, Dudley Group Hospitals, Dudley, DY1 2HQ, United Kingdom

Fax: +441384244262

sauid.ishaq@nhs.net

\section{ABSTRACT}

Background and aim As the post-peak phase of the epidemic is approaching, there is an urgent need of an action plan to help resume endoscopy activity. To manage the Covid-19 pandemic-imposed backlog of postponed colonoscopy examinations, an efficient approach is needed. The practice of on-demand sedation with benzodiazepines and/or opiates will allow most patients to complete a water-aided examination with minimal or no sedation. Other methods reported to minimize patient discomfort during colonoscopy can be used, in addition to water-aided techniques. Unsedated or minimally sedated patients who do not require recovery or require a shorter one allow rapid turnaround. The practice obviates the need for assistance with deep sedation from anesthesiologists, who may be in short supply. Trainee education in water-aided colonoscopy has been demonstrated to confer benefits. This review provides some insights into the impact of Covid-19 on endoscopy services, challenges ahead, and possible solutions to help recovery of colonoscopy work and training.

\section{Background}

The Covid-19 pandemic presents danger and threat to humans. No efforts have been spared to contain this global threat. Many countries imposed a lockdown to flatten the outbreak curve, hoping to reduce hospital admissions and prevent chaotic clo- 


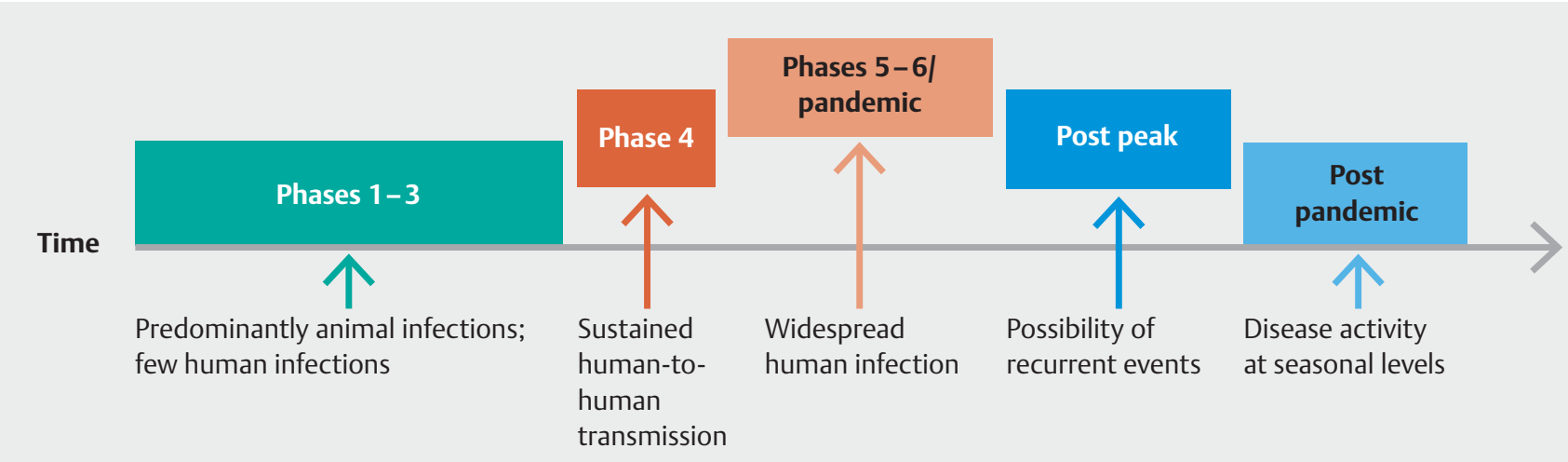

- Fig. 1 The WHO classification of phases of pandemic.

sures of intensive care units. To deal with the deluge of Covid19 patients, hospitals have suspended all elective and non-essential activity, and specialty staff have been redeployed to deal with the crisis. This helped to minimize risk to other patients and personnel. With a vaccine not in sight, it remains unknown when and how it will be possible to resume normal activities. Although routine endoscopy referrals were deferred, emergency and essential endoscopy activity were carried out mostly in secondary and tertiary hospitals. In daily practice, this resulted in build-up of referrals and postponement of screening for colorectal cancer. The approach of individual centers, until now, has been to mitigate patients' risk for any delay in diagnosis and treatment.

As the post-peak phase of the pandemic may be approaching, there is an urgent need to limit collateral damage associated with delaying routine endoscopy. In this article, we focus on colonoscopy. We must be able to deliver the service correctly, mainly by triaging and deciding which patients should undergo the procedure more urgently and for whom it can be deferred, being conscious that some cases have high risk of complications which would be more difficult to be deal with than in a time not impacted by Covid-19. If the epidemic is prolonged, it will be necessary to look not only to the patients but also at the needs of trainees, as elective procedure numbers will be drastically reduced. We are passing through five to six phases of the pandemic ( $\mathbf{F i g . 1}$ ), with expectation and hope to move to the post-peak and the post-pandemic phases in the next few months.

\section{Urgent work during Covid-19 emergency}

Endoscopy units face significant risks and challenges. Recent position statements from some endoscopy societies warned about the significant exposure to droplets from patients during maneuvers requiring close contact (less than 1 meter), e. g. resuscitation maneuvers and endoscopy, particularly if they last more than 15 minutes [1-3]. Droplets can reach people located approximately 1.8 meters or more from the source [4]. Viral shedding has been recognized in stools in almost half of the pa- tients infected by Covid-19, even after their respiratory symptoms had disappeared [5].

Many endoscopy units have adopted use of protective personal equipment (PPE), such as hairnet, gloves (two pairs), goggles and/or face shields, waterproof gowns, and specifically N95 filtering face pieces (FFPs) 2 or FFP3 respirators, while treating Covid-19-suspected or -positive cases. Standard medical or surgical facial masks, or face shielding in general, can be used for low risk or for negative cases [2,3].

However, because in the current phase of the pandemic there is a high rate of asymptomatic patients, most endoscopy units have adopted "full PPE". Also in case of emergency procedures on outpatients, due to the possibility to come in contact with false negatives, most endoscopists have adopted the strategy of using the same protections suggested for positives. During recovery, we need to be cautious about risk of infection. A strict protocol for screening and identifying patients at risk should be followed. Use of surgical masks, gloves, and aprons should continue, and enhanced PPE have to be worn during procedures on intermediate- and high-risk patients.

\section{Resuming elective work after the Covid-19 emergency}

After the lockdown, countries and hospitals will have to reopen. Patients may be reluctant to come back to hospitals due to the negative image they created as a potential source of infection by Covid-19. Thus, policies must be in place to restore trust from the general population towards hospitals (e.g. using extensive testing of health care personnel and patients). It will probably be advisable to plan low-risk and/or screening endoscopies on different days from those allocated for intermediaterisk and Covid-positive patients to separate these different endoscopy subgroups.

However, there will be a great demand, especially among high-risk patients, for procedures as a result of the backlog created when testing stopped because of the Covid-19 epidemic. Unfortunately, due to Darwinian selection, an increase in advanced neoplasia and more advanced resections might be expected. Hence, it is going to be ever more important that we 
strive to be highly efficient to make up for the lost work during the Covid-19 pandemic, while maintaining a high level of quality. One of the most important actions to take will be resuming colorectal cancer screening colonoscopies, to maintain the positive results achieved in the last decade [6].

It will be even more important in the aftermath of the Covid19 epidemic to decrease as much as possible the number of incomplete or low-quality procedures so as to reduce the need to reschedule them, which would increase patient exposure to potential infection. The most vulnerable patients are those in whom it is more difficult to achieve high-quality examinations.

The Covid-19 epidemic overwhelmed most departments in general, and the anesthesia departments in particular, and they will be too busy returning to regular work and catching up with the backlog. This might impact the ability of the anesthesiology departments to help with administration of deep sedation. In addition, problems arise due to global shortage of drugs needed to treat Covid-19-positive patients on ventilators, among others. Furthermore, national institutions are stocking up anesthetic medications to cope with a possible second wave of the epidemic. Because of the soaring demand for these medications, the US Food and Drug Administration went even further, relaxing rules for outsourcing drugs and even allowing a set of default beyond use dates based on the processing and storage conditions of the drugs for compounders to use [7].

Perhaps we have to look at other options, such as using ondemand sedation with opioids and/or benzodiazepines that can be administered by endoscopy personnel. The discomfort reported by patients during the procedure is mainly due to instrument looping and to excessive distension of the colon. The latter causes bloating and related abdominal pain, which also may affect patients after the procedure. Compared with air insufflation colonoscopy (AIR), $\mathrm{CO}_{2}$ insufflation produces significantly less bloating and pain in the post-procedure period $[8,9]$, but has been reported to be ineffective in decreasing pain during instrument insertion in patients undergoing unsedated colonoscopy or in procedures with different approaches to sedation [10] performed by experienced colonoscopists.

Perhaps this is a good time to consider adopting low-cost interventions to minimize risk of transmission of the Covid-19 virus, decrease the number of incomplete or low-quality procedures that require rescheduling, and minimize the need for anesthesia medication and support. Low-cost interventions have been proven effective [11].

One such low-cost intervention that has been proven to increase the quality of colonoscopy is water-aided colonoscopy (WAC) [11]. Using WAC during the insertion phase, less or no positive pressure is introduced into the bowel by use of gas insufflation, decreasing the probability of generating droplet diffusion by flatus. Towels or pads will easily adsorb effluents, avoiding their spread at a distance. However, it is paramount to remember the importance of adequate PPE by staff performing and assisting in colonoscopy. No procedure should be done, even in non-pandemic times, without adequate face shielding, and a long-sleeve gown.

Any variation of WAC is significantly less painful than the usual gas insufflation colonoscopy and decreases need for se- dation [10]. The technique known as water immersion (WI) is easiest to implement, as described by Japanese endoscopists who used it routinely three decades ago. The usual tools of insertion can be combined with water infusion, gas removal and/ or insufflation based on patient comfort, pursuing procedure efficiency by moving forward when the luminal view is adequate, tailoring the colonoscopy to the sedation level, bowel preparation, patient anatomy, and colonoscopist preference. Indeed, a leading world expert on colonoscopy considered it ideal for simplifying cecal intubation in patients with redundant colons and previously incomplete procedures [12]; many colonoscopists use it to facilitate scope advancement in difficult colonoscopy. The WAC technique called water exchange (WE) completely eliminates use of gas insufflation during insertion, entailing gasless progression to the cecum in clear water. This technique requires more skills and WI can be considered as propaedeutic to WE $[9,10,13]$.

An additional benefit of on-demand or unsedated WAC is significantly reduced recovery time, and hence less exposure patient exposure in a high-risk environment such as the endoscopy recovery unit.

Other low-cost effective interventions are double-checking the right colon and rectum (in forward view and/or retroflexion); use of patient position change; and slow scope withdrawal to allow careful inspection behind any fold along with adequate lumen distension [11]. This approach might require just a marginal increase in time and effort. Finally, predictive scores for poor preparation are not being used in clinical practice; however, in the current scenario, they could potentially assist in predicting which patients are at risk for poor preparation. A tailored bowel preparation could be recommended for them.

Other effective methods to decrease patient anxiety and discomfort during colonoscopy are listening to music [14]; hypnosis; and inhalation of nitrous oxide, which improves the patient experience during the procedure and is rapidly eliminated [14, 15], minimizing after effects and inconvenience to patients. Although nitrous oxide has not been considered to generate aerosol, this has not been investigated in research studies [16].

\section{Resuming training work after Covid-19 emergency}

Any advances in endoscopic technique that render colonoscopy easier, diminishing discomfort and minimizing the need for sedation in trainee-performed procedures, have the potential to improve their performance while making the examination safer. With the reduction in the number of procedures adequate for training, and also considering that the procedures should be as efficient as possible, strategies to optimize training should be developed. This may also be a good moment to rethink the methods applied in endoscopy teaching and training, which are complex exercises that should be optimized, especially now [17], adapting them to the Covid-19 situation. There should be clear learning objectives, and the trainer and trainee should align their agendas. Frequently, the method used for teaching colonoscopy is allowing trainees to start the colonoscopy, giving them indications when facing difficulties, 
and eventually taking over when the agreed time as been exceeded. However, this is not the only possible method and probably not the best one.

To optimize the teaching episode, other alternatives previously described are available. When the attending colonoscopists become comfortable with WAC, they can consider teaching trainees as appropriate conditions arise. Others have also reported favorably on trainee education about WAC [18-20]. WAC could be taught in the current situation, because a trainee could be allowed to practice during part of the WAC colonoscopy, not the whole procedure, and therefore acquire competence in the technique progressively, without increasing procedure duration.

\section{WAC tricks and tips for the beginner and self-learner}

As we alluded, many colonoscopists use water immersion to facilitate scope advancement in difficult colonoscopy, and hence they are no strangers to this concept. Water exchange, on the other hand, requires new sets of skills and a training period [13]. However, it can be easily learned when the correct technique, tips, and tricks proposed by experts are followed [13]. For experienced colonoscopists, the learning curve is about 50 cases; cecal intubation times can approach baseline after about 100 cases. In videos (Video 1 [https://doi.org/10.1016/j. vgie.2018.02.004] and Video 2 [https://doi.org/10.1016/j. vgie.2019.03.021], available online at www.VideoGIE.org), we offer a pragmatic guide on how to perform WI and WE in daily practice, along with some tips and tricks (Video 2) that readers may find helpful.

\section{Conclusion}

It is truly a challenging time for the world. We healthcare workers are determined to take on additional reasonability, not only to deal with the Covid-19 pandemic, but also to reopen as early as possible to serve patients not infected with Covid-19 so as to mitigate risk of delayed diagnosis and treatment. By doing so, we are duty bound to ensure that our patients are protected from the spread of infection. Colonoscopy is an endoscopic technique in great demand. Strategies to maximize quality, reduce repeat procedures, improve patient experience while reducing risk of infection to the endoscopy team, and ensure sufficient capacity are required. Training in colonoscopy has to continue, and innovative approaches should be considered to optimize it. We have to learn to innovate, adapting to new techniques and equipment to reduce our patients' hospital stays and exposure to a high-risk environment.

\section{Competing interests}

The authors declare that they have no conflict of interest.

\section{References}

[1] Istituto Superiore di Sanità. Interim guidance for rational use of SARSCOV-2 infection protections in health and socio-health activities in the current SARS-COV-2 emerging scenario. Version of May 10, 2020 (in Italian). Online (last accessed: 24.05.2020): https://www.iss.it/ documents/20126/0/Rapporto+ISS+COVID+2_+Protezioni_REV+2. pdf/318ebe4a-6b1e-dc6e-fa19-434658a92df3?t=1589836417348

[2] Chiu PWY, Ng SC, Inoue $\mathrm{H}$ et al. Practice of endoscopy during COVID19 pandemic: position statements of the Asian Pacific Society for Digestive Endoscopy (APSDE-COVID statements). Gut 2020; 69: 991996

[3] Gralnek IM, Hassan C, Beilenhoff $U$ et al. ESGE and ESGENA position statement on gastrointestinal endoscopy and the COVID-19 pandemic. Endoscopy 2020: [Epub ahead of print] doi:10.1055/a-11556229

[4] Johnston ER, Habib-Bein N, Dueker JM et al. Risk of bacterial exposure to the endoscopist's face during endoscopy. Gastrointest Endosc 2019; 89: 818-824

[5] Cheung KS, Hung IF, Chan PP et al. Gastrointestinal manifestations of SARS-CoV-2 infection and virus load in fecal samples from the Hong Kong cohort and systematic review and meta-analysis. Gastroenterology 2020: [Epub ahead of print] doi:10.1053/j.gastro.2020.03.065

[6] Lauby-Secretan B, Vilahur N, Bianchini F et al. The IARC perspective on colorectal cancer screening. N Engl J Med 2018; 378: 1734-1740

[7] Regulations.gov. Temporary policy for compounding of certain drugs for hospitalized patients by outsourcing facilities during the COVID19 public health emergency - Guidance for the industry. Online (last accessed: 24.05.2020): https://www.fda.gov/regulatory-information/search-fda-guidance-documents/temporary-policy-compounding-certain-drugs-hospitalized-patients-outsourcing-facilities-during-covid

[8] Bretthauer M, Hoff GS, Thiis-Evensen E et al. Air and carbon dioxide volumes insufflated during colonoscopy. Gastrointest Endosc 2003; 58: 203-206

[9] Cadoni S, Gallittu P, Leung FW et al. Impact of carbon dioxide insufflation and water exchange on postcolonoscopy outcomes in patient receiving on demand sedation: a randomized controlled trial. Gastrointest Endosc 2016; 85: 1-9

[10] Fuccio L, Frazzoni L, Hassan C et al. Water exchange colonoscopy increases adenoma detection rate: a systematic review with network meta-analysis of randomized controlled studies. Gastrointest Endosc 2018; 88: 589-597.e11

[11] Facciorusso A, Triantafyllou K, Murad MH et al. Compared abilities of endoscopic techniques to increase colon adenoma detection rates: a network meta-analysis. Clin Gastroenterol Hepatol 2019; 17: 24392454

[12] Vemulapalli KC, Rex DK. Water immersion simplifies cecal intubation in patients with redundant colons and previous incomplete colonoscopies. Gastrointest Endosc 2012; 76: 812-817

[13] Friedland S, Leung FW. Learning and teaching the water method (with videos). J Interv Gastroenterol 2011; 1: 127-129

[14] Leung FW. Methods of reducing discomfort during colonoscopy. Dig Dis Sci 2008; 53: 1462-1467

[15] Domínguez-Ortega L, Rodríguez-Muňoz S. The effectiveness of clinical hypnosis in the digestive endoscopy: A multiple case report. Am J Clin Hypn 2010; 53: 101-107

[16] Bampoe S, Odor PM, Lucas DN. Novel coronavirus SARS-CoV-2 and COVID-19. Practice recommendations for obstetric anaesthesia: What We have learned thus far. Int J Obstet Anesth 2020; 43: 1-8

[17] Waschke KA, Anderson J, Macintosh D et al. Training the gastrointestinal endoscopy trainer. Best Pract Res Clin Gastroenterol 2016; 30: 409-419 
[18] Leung CW, Kaltenbach T, Soetikno R et al. Water immersion versus standard colonoscopy insertion technique: randomized trial shows promise for minimal sedation. Endoscopy 2010; 42: 557-563

[19] Ngo C, Leung JW, Mann KS et al. Interim report of a randomized crossover study comparing clinical performance of novice trainee endos- copists using conventional air insufflation versus warm water infusion colonoscopy. J Interv Gastroenterol 2012; 2: 135-139

[20] Azevedo R, Leitão C, Pinto J et al. Can water exchange improve patient tolerance in unsedated colonoscopy a prospective comparative study. GE Port J Gastroenterol 2018; 25: 166-174 